\title{
ARE AI TOOLS GOING TO BE THE NEW DESIGNERS? A TAXONOMY FOR MEASURING THE LEVEL OF AUTOMATION OF DESIGN ACTIVITIES
}

\author{
S. Altavilla ${ }^{1, \bigotimes}$ and E. Blanco ${ }^{2}$ \\ ${ }^{1}$ Politecnico di Torino, Italy, ${ }^{2}$ Université Grenoble Alpes, France \\ $\bigotimes$ stefania.altavilla@polito.it
}

\begin{abstract}
The digitalisation of the industry offers new opportunities to discuss design activities and support tools. Advancement in AI allows thinking about new Designer-AI tools interaction in the design process. The paper aims to initiate a characterisation of tools issued from researches in the application of AI in Design to rethink the division of work between Designer-AI tools. The paper is based on the literature on the concept of Levels of Automation in cognitive engineering, manufacturing and robotics, and proposes a grid of characterisation of the Level of Automation for the design process.
\end{abstract}

Keywords: design automation, computational design methods, design support system, level of automation

\section{Introduction}

With the increasing number of information to be processed during design, the information processing capabilities of humans becomes rapidly overloaded (Seidel et al., 2018). Moreover, the complexity of systems/product to be developed is increasing, which leads to the necessity of having automated support tools that can be integrated during the entire design processes (Breton and Bosse, 2003). Therefore, the combination of human (seen as the decision-maker) and the automated tool (seen as the decision aid) represent the ideal solution that maximizes the advantages of additional cognitive power in a decision-making process, as the design one (Seidel et al., 2018).

In the classical vision, the designer has always been seen as the cognitive system. With the advances in computational technology, already back during the ' $80 \mathrm{~s}$, attempts have been made in the development of artificial cognitive systems, which represent tools that perform tasks normally associated only with human cognition (Woods, 1985). With the recent development of AI techniques, there is a concrete chance to develop a new generation of "artificial" cognitive systems.

These algorithms allow on the one hand to develop more advanced products, and on the other hand, to avoid waste and to generate more lean and automated processes. In fact, we are discussing the automation of processes, which also affects the design one. Indeed, by the automation of the design process, we refer to the ability of some AI and Machine Learning algorithms to carry out, independently, some of the design tasks, not only in the most cumbersome and repetitive activities of solutions evaluation, the ranking of alternatives but also in the generation of ideas.

The automated tools have, from one hand, the benefit to support deductive reasoning capability, hence easily assessing a high number of alternative simultaneously. Moreover, these tools have an enormous 
data storage and computational capabilities, which make them able to provide different kind of prescriptive analysis that humans have neither the time nor the ability to do. However, AI tools are still missing inductive reasoning, which is usually related to human creativity. Humans, in fact, can hardly deal with several hypotheses at the same time but have the capacity to make inductive reasoning.

A naive view suggests these automated tools will someday replace designers in the design process. An alternative perspective is that designers will continue to play an important role but also that this role is changing (Seidel et al., 2018), and hence the interaction between the automated systems and the human must be established.

Therefore, this paper aims at looking at the interaction Designer-AI Tool in the execution of tasks, and in particular of design tasks. To this purpose, we have used the concept of automation level, which allows measuring the degree of interaction human-automated tool. Several taxonomies have been developed on the levels of automation (LOAs) (see Vagia et al., 2016 for a review). The reference literature is mostly related to the Automation literature and Cognitive Engineering. According to our research, the concept has not yet been further developed in the Design literature. Therefore, this paper has the further purpose of:

- Review the LOAs literature, so to understand the differences and benefits of the different taxonomies presented so far.

- Suggest a new LOA taxonomy that would be dedicated to analysing human-machine interaction within the design process.

The paper is then organised as follows; Section 2 outlines the literature review on LOAs taxonomies in different streams of the literature. In the end, the section identifies the possible LOA that could be taken as a reference in the definition of a new taxonomy for measuring the degree of automation in the design process. Section 3 proposes a review on the cognitive models of the design process to select a baseline for modelling generic activities of designing. A suggestion for the definition of a LOA taxonomy for design contexts is proposed in Section 4, while Section 5 illustrates two examples of LOA assessment. The overall conclusions and future development are discussed in Section 6.

\section{Literature review on the LOAs' taxonomies}

The literature on Levels of Automation (LOAs) has been extensively discussed, starting from a pioneering publication by Sheridan and Verplank (1978). The idea that drives the concept of LOAs is in its intrinsic capacity of being a design characteristic (Kaber, 2018), which is aimed to guide designers in the creation of effective human-automation interaction for autonomous systems (Bradshaw et al., 2013). In particular, LOA taxonomies have been employed extensively to understand the effect of automation on human cognition and performances. Moreover, in the cognitive engineering literature, different are the models that have been developed on the humanautomation interaction in complex systems. Some of these models characterise types and levels of automation (LOAs) and relate different LOAs to implications for human performance, workload, and situation awareness as bases for systems design (Kaber, 2018).

The purpose of defining a measure for the level of automation is also functional to the need of understanding how to allocate the work, between humans and the automated tool, within a task. Hence, the issue of task allocation is one of the main reasons that moved the interest of researchers in this area. In general, the assignment is determined based on the performances of both humans and the automated system, observing the specific requirements needed in the execution of an activity, which are usually related to the cognitive effort, the demands for problem-solving, or the physical strength (Fitts, 1951). Hence, when the performance of one category exceeds that of the other, some tasks have to be allocated to the machine or the human (Fitts, 1951). In cases in which the human or the automated system need support from each other, the allocation of the workload is distributed between the two categories.

However, as also argued by several authors (Miller and Parasuraman, 2007; Kaber, 2018), the relationship between the level of automation and the division between tasks is generally more 
complex. This is because automation impacts the very nature of the activity and the sequence of activities and sub-activities in a process. In fact, some tasks will be eliminated entirely by automation, while others could be generated.

Therefore, on the one hand, it is necessary to revise the processes (whether design, production, logistics, etc.) entirely according to the automation. On the other hand, it is also essential to provide measuring instruments for the level of automation that can adapt to the type of process analysed. Each alternative constitutes a different combination of human and automation subtasks and, thus, a different method of accomplishing the parent task.

In reviewing the literature on the LOAs, two dimensions have been identified, which can be helpful in organizing the different taxonomies provided so far. The two dimensions are respectively:

- The class of automation, as proposed by Chiantella (1982), Williams (1999) and Frohm et al. (2008). This dimension differentiates the LOAs based on two variables, i.e. the Mechanization and the Computerization;

- The aspect of the automation, as supported by Johnson et al. (2011), Bradshaw et al. (2013) and Kaber (2018). This category relates to the function decomposition in a task, distinguishing between Unidimensional and Multidimensional models.

Figure 1 shows the two dimensions that can be used to classify the different LOAs. Accordingly, the taxonomies reviewed in this paper have been placed in the most representative quadrants.

The horizontal axe, in Figure 1, identifies the two classes belonging to the first dimension, namely Computerisation and Mechanization (Chiantella, 1982; Williams, 1999; Frohm et al., 2008). The former looks at the automated process from the side of the information that is collected, stored, analysed and used. Hence, the taxonomies provided in this area (e.g. CM and CU quadrants in Figure 1) are concentrate on the human-computer interaction, where the automated tool aims at replacing the cognitive tasks, such as human sensory processes and mental activity (Frohm et al., 2008). Mechanization, instead, relates to the operativity of the process, accounting for the activities of producing, supervising and problem-solving. The different levels of automation (e.g. taxonomies in the MM and MU quadrants), in fact, reflect the replacement of human physical and control power over the tasks in a process (Williams, 1999).

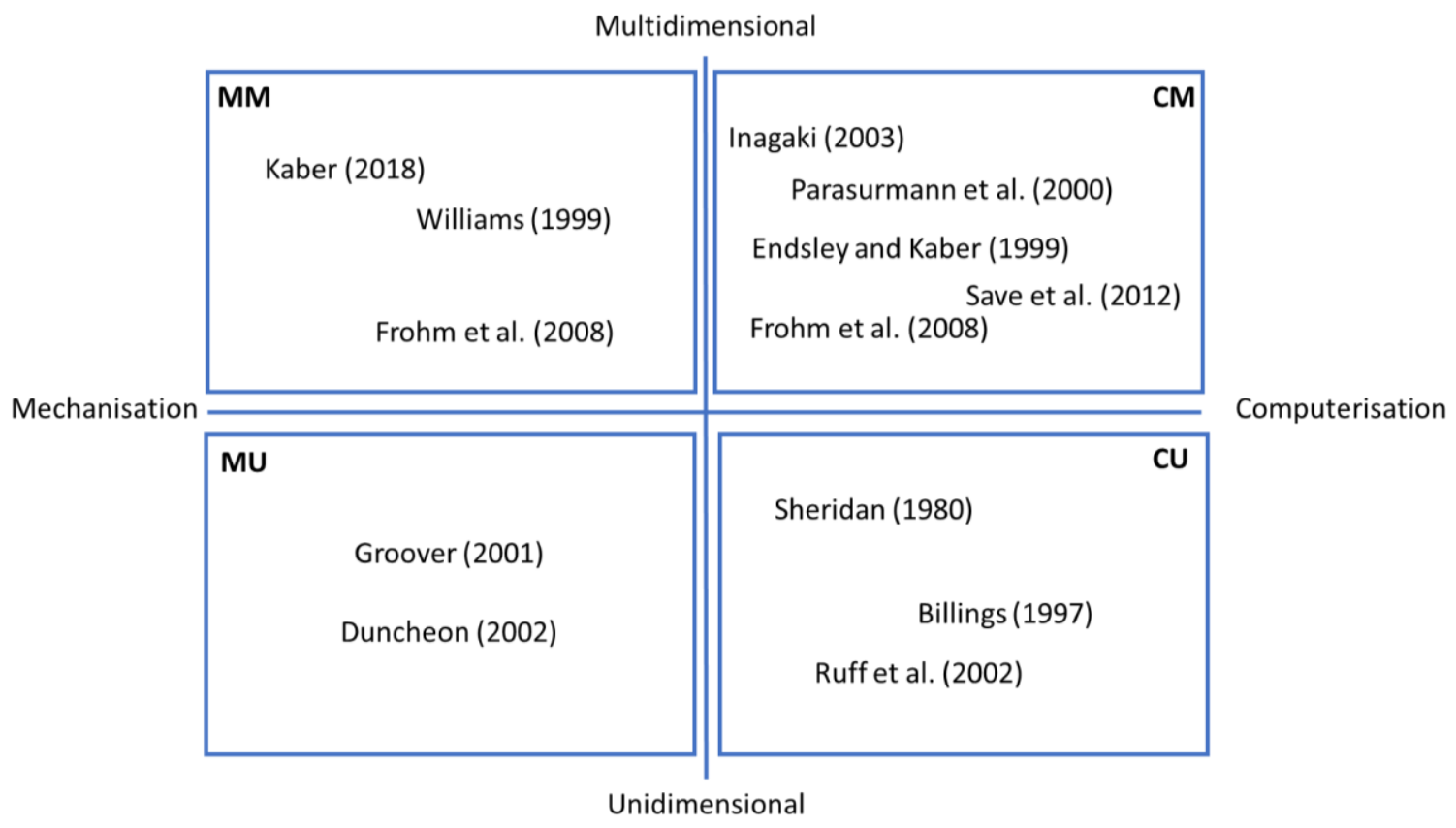

Figure 1. The four identified variables for analysing LOAs taxonomies

The vertical axe depicts in Figure 1 accounts for the dimension of automation. Here, the LOAs taxonomies have been divided between Unidimensional (quadrants CU and MU) and Multidimensional models (quadrants $\mathrm{CM}$ and $\mathrm{MM}$ ), looking at the application domain of the relationship between human 
and the automated system. Unidimensional taxonomies focus mainly on a particular application and consequently on a single human-system relationship. Examples are mostly devoted to LOAs that guide the automation in making decisions (Ruff et al., 2002; Duncheon, 2002) or offering suggestions (Sheridan, 1980, Billings, 1997) or executing actions (Groover, 2001).

However, many authors argue that automation is, by definition, multidimensional (Johnson et al., 2011; Bradshaw et al., 2013).

First of all, several functions can be performed in each task, and levels of automation can be defined for each of them. Moreover, the level of automation cannot be expressed as a dichotomous variable but should be rather seen as a continuum of the levels of automation. In this case, the lower bound is expressed as the level of wholly manual performance, while the upper bound refers to full automation without any human involvement. Secondly, at least two dimensions can be attributed to autonomous systems, and in particular the self-sufficiency (the ability to operates without outside help) and the self-directedness (e.g. freedom from outside control). Both must be balanced in the performance of the different functions within a single activity. Some functions can, therefore, be carried out autonomously (high self-sufficiency). Other, instead, require a possible manual intervention by an operator and therefore require a low level of self-directness. Hence, in each case, a decision on which functions to automate and to what degree of autonomy should be taken.

The aspects of multidimensionality had been developed mainly in the analysis of robots in the manufacturing context, or autonomous cars, or air traffic management in the transport sector.

With the aim of developing a taxonomy suitable for the design process, both the aspect of multidimensionality and the aspect of computerisation are to be taken into account, thus concentrating on the quadrant CM in Figure 1. The former is because, in general, the design process is by nature based on several activities, which must be considered independently from the point of view of automation. Therefore, the right level of automation must be associated with each activity. In addition, the design process is, by nature a cognitive process. Of course, one can argue that design activity can include hands working, prototyping, body engagement or material transformation and thus mechanization should also be considered. Yet we'll consider only cognitive activities in our proposal.

Moreover, we need to identify the appropriate model of the design process. In particular, we need a model that is able to describe the main activities in the process, taking into account the behaviour of the designer in performing a single task. This last aspect is particularly crucial since our research has the final aim to clarify better how the tool can somehow support/replace the designer in his/her work. This last point is addressed in the next session.

\section{The reference model of activities of the design process}

In general, the design process models can be categorised into descriptive, prescriptive and computer-based (Takeda et al., 1990). The descriptive and prescriptive models explain, accordingly how the design is done and how the design must be done. Finally, the computer-based models concentrate on the methodology by which a computer can perform a task.

On this last category, a lot has been investigated in the cognitive science research (Finger and Dixon, 1989). The goal, in fact, was to develop computer-based models that emulate the skills that humans use in problem-solving. Hence, the cognitive models propose descriptive solutions of cognitive systems at its functional mechanism, generating explanations and predictions on the human skills being studied (Finger and Dixon, 1989).

Srinivasan and Chakrabarti (2010) proposed a review of the literature on the different cognitive models. In particular, they focus their attention on identifying the different kinds of contributions on activities definition. In general, each design process has its own activity, but they can be seen from a more general point of view, which can be sufficient in order to describe designing.

Among the different model of the activities available in the literature, we select the GEMS one proposed by Srinivasan and Chakrabarti (2010). Four are the generic activities considered: Generate, Evaluate, Modify and Select. The activity model is depicted in Figure 2. 


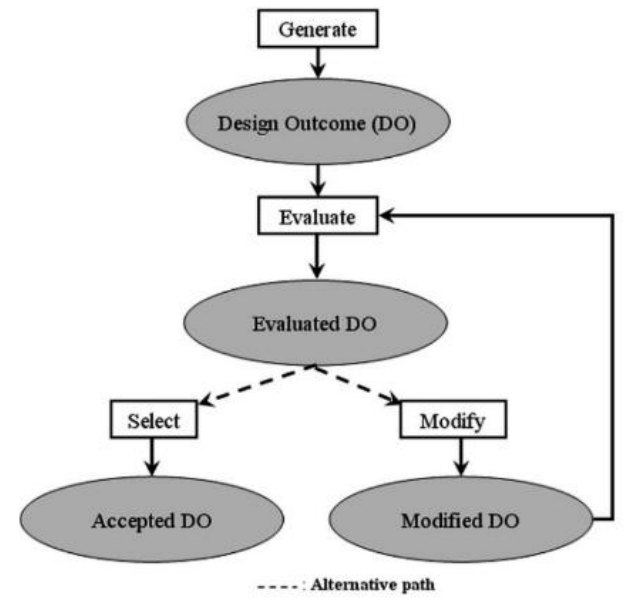

Figure 2. The GEMS activity model by Srinivasan and Chakrabarti (2010)

As shown in Figure 2, another element composes the GEMS model, which is related to the design outcome. In fact, each activity aims to generate, evaluate, modify and select a design outcome. However, during the design process, designers face different levels of abstraction, which lead to different design outcomes. Hence, different outcomes should be taken into account, considering the different abstraction levels. These outcomes become more detailed with the reduction of the abstraction during the progress of the design process.

\section{A grid to characterize the level of design process automation}

After the identification of the function types, the levels of automation for design activities have been identified following the approaches of Parasuraman et al. (2000), Proud et al. (2003) and Save et al. (2012).

The proposed LOA scale is bounded between Levels 1 and 5, as showed in Table 1, which correspond to the complete control of the activity respectively by the Designer (low degree of automation) or by the Automated Tool (high degree of automation). In particular, the LOA can be broken down into three sections. In Levels 1-2, the designer is primary, and the AI tool is secondary. In Level 3, the designer operates, interacting with the tool. In Levels 4-5, the tool operates independently of the designer, and he/she has decreasing access to information.

Table 1. The five levels of design process automation

\begin{tabular}{|c|c|l|}
\hline Degree of Automation & Level of Autonomy & Description \\
\hline \multirow{3}{*}{$\begin{array}{c}\text { LOW } \\
\text { HGH }\end{array}$} & Level 1 & Designer \\
\cline { 2 - 3 } & Level 2 & $\begin{array}{l}\text { Designer (Direction - Partial Execution) / Computer } \\
\text { (support to the execution) }\end{array}$ \\
\cline { 2 - 3 } & Level 3 & Designer (Direction) / Computer (Execution) \\
\cline { 2 - 3 } & Level 4 & Designer (Execution) / Computer (Direction) \\
\cline { 2 - 3 } & Level 5 & Computer Direction and Execution \\
\hline
\end{tabular}

As shown in Table 1, the proposed five levels of automation present a further distinction that takes into account aspects of self-sufficiency and self-directedness. In fact, compared to other taxonomies in the literature, our proposal considers two different levels of collaboration and interaction between the Designer and the AI Tool, namely the Direction and the Execution. The Direction accounts for the self-directedness aspects and, therefore, looks at who between the designer and the tool defines the task's objectives. The execution, instead, takes into account the elements of self-sufficiency, looking at who performs the work in each individual activity.

The designer can define the objectives, hence maintaining the direction of a task, while leaving to the AI tool the support in its execution (or even the full release). Differently, the AI tool can integrate both the objectives' definition (Direction) and the autonomous realisation of the activity (Execution). 
Hence, the proposed LOA taxonomy covers the different degree of collaboration between the designer and the tool, which allow going beyond the simple binary vision of automated or not.

Table 2. The grid to characterise the levels of design process automation

\begin{tabular}{|c|c|c|c|c|}
\hline \multirow{2}{*}{$\begin{array}{c}\text { Level of } \\
\text { Autonomy }\end{array}$} & \multicolumn{4}{|c|}{ GEMS Activities } \\
\hline & Generation & Evaluation & Modification & Selection \\
\hline \multirow[t]{2}{*}{ Level 1} & Designer & Designer & Designer & Designer \\
\hline & $\begin{array}{l}\text { The designer alone } \\
\text { can generate the } \\
\text { design outcome. }\end{array}$ & $\begin{array}{l}\text { The designer is the only } \\
\text { source for analysing all } \\
\text { data, and the check of } \\
\text { the design outcome } \\
\text { suitability considering } \\
\text { some criteria. }\end{array}$ & $\begin{array}{l}\text { The designer reviews the } \\
\text { design outcome and } \\
\text { modifies it on the basis of } \\
\text { criteria which have not } \\
\text { been met. }\end{array}$ & $\begin{array}{l}\text { The designer alone } \\
\text { selects the final design } \\
\text { outcome after its } \\
\text { revision by deciding if } \\
\text { it is acceptable or } \\
\text { unacceptable. }\end{array}$ \\
\hline \multirow[t]{2}{*}{ Level 2} & $\begin{array}{l}\text { Designer (Direction - } \\
\text { Partial Execution) / } \\
\text { Computer (support to } \\
\text { the execution) }\end{array}$ & $\begin{array}{c}\text { Designer (Direction - } \\
\text { Partial Execution) / } \\
\text { Computer (support to } \\
\text { the execution) }\end{array}$ & $\begin{array}{c}\text { Designer (Direction - } \\
\text { Partial Execution) / } \\
\text { Computer (support to } \\
\text { the execution) }\end{array}$ & $\begin{array}{l}\text { Designer (Direction - } \\
\text { Partial Execution) / } \\
\text { Computer (support to } \\
\text { the execution) }\end{array}$ \\
\hline & $\begin{array}{l}\text { The designer is the } \\
\text { prime source of } \\
\text { generation, with the } \\
\text { computer shadow for } \\
\text { contingencies (e.g. } \\
\text { providing the support } \\
\text { in looking for the } \\
\text { required information). }\end{array}$ & $\begin{array}{l}\text { The designer performs } \\
\text { all checking against the } \\
\text { criteria suitability of the } \\
\text { design outcome. The } \\
\text { tool is used for } \\
\text { assistance. }\end{array}$ & $\begin{array}{l}\text { The designer is the prime } \\
\text { source for the design } \\
\text { outcome modification, } \\
\text { with the tool shadow for } \\
\text { contingencies. The } \\
\text { designer is responsible for } \\
\text { the interpretation of the } \\
\text { data. }\end{array}$ & $\begin{array}{l}\text { The designer alone } \\
\text { selects the final design } \\
\text { outcome after its } \\
\text { revision, and the tool is } \\
\text { used for assistance. }\end{array}$ \\
\hline \multirow[t]{2}{*}{ Level 3} & $\begin{array}{l}\text { Designer (Direction) / } \\
\text { Computer (Execution) }\end{array}$ & $\begin{array}{l}\text { Designer (Direction) / } \\
\text { Computer (Execution) }\end{array}$ & $\begin{array}{l}\text { Designer (Direction) / } \\
\text { Computer (Execution) }\end{array}$ & $\begin{array}{l}\text { Designer (Direction) / } \\
\text { Computer (Execution) }\end{array}$ \\
\hline & $\begin{array}{l}\text { The tool generates the } \\
\text { design outcome after } \\
\text { the designer approval. } \\
\text { The designer shadow } \\
\text { for contingencies. }\end{array}$ & $\begin{array}{l}\text { The tool is the prime } \\
\text { source of analysis on the } \\
\text { suitability of the design } \\
\text { outcome. The designer } \\
\text { is responsible for the } \\
\text { interpretation of the } \\
\text { data. }\end{array}$ & $\begin{array}{c}\text { The tool is the prime } \\
\text { source for the design } \\
\text { outcome modification, } \\
\text { with the designer shadow } \\
\text { for contingencies. The } \\
\text { designer is responsible for } \\
\text { the interpretation of the } \\
\text { data. }\end{array}$ & $\begin{array}{l}\text { The tool selects the } \\
\text { final design outcome } \\
\text { after its revision, and } \\
\text { the designer is used for } \\
\text { assistance. Still the } \\
\text { designer's approval is } \\
\text { necessary. }\end{array}$ \\
\hline \multirow[t]{2}{*}{ Level 4} & $\begin{array}{l}\text { Designer (Execution) / } \\
\text { Computer (Direction) }\end{array}$ & $\begin{array}{l}\text { Designer (Execution) / } \\
\text { Computer (Direction) }\end{array}$ & \begin{tabular}{|c|} 
Designer (Execution) / \\
Computer(Direction)
\end{tabular} & $\begin{array}{c}\text { Designer (Execution) / } \\
\text { Computer (Direction) }\end{array}$ \\
\hline & $\begin{array}{l}\text { The designer } \\
\text { generates the design } \\
\text { outcome. The tool } \\
\text { establishes the } \\
\text { boundary of the } \\
\text { generation space. }\end{array}$ & $\begin{array}{l}\text { The designer is the only } \\
\text { source for analysing all } \\
\text { data, and the check of } \\
\text { the design outcome } \\
\text { suitability considering } \\
\text { some criteria. The tool } \\
\text { provides the boundaries } \\
\text { for defining the } \\
\text { suitability }\end{array}$ & $\begin{array}{l}\text { The designer reviews the } \\
\text { design outcome and } \\
\text { modifies it on the basis of } \\
\text { criteria which have not } \\
\text { been met. The tool } \\
\text { defines the limits for the } \\
\text { modification }\end{array}$ & $\begin{array}{l}\text { The designer selects } \\
\text { the final design } \\
\text { outcome after its } \\
\text { revision by deciding if } \\
\text { it is acceptable or } \\
\text { unacceptable. The tool } \\
\text { provides the } \\
\text { boundaries for the } \\
\text { definition of } \\
\text { acceptability. }\end{array}$ \\
\hline \multirow[t]{2}{*}{ Level 5} & $\begin{array}{c}\text { Computer Direction } \\
\text { and Execution }\end{array}$ & $\begin{array}{c}\text { Computer Direction and } \\
\text { Execution }\end{array}$ & $\begin{array}{c}\text { Computer Direction } \\
\text { and Execution }\end{array}$ & $\begin{array}{c}\text { Computer Direction } \\
\text { and Execution }\end{array}$ \\
\hline & $\begin{array}{l}\text { The tool generates the } \\
\text { design outcome } \\
\text { automatically and } \\
\text { does not need any } \\
\text { designer interaction }\end{array}$ & $\begin{array}{l}\text { The tool analyses all the } \\
\text { information and } \\
\text { evaluates the design } \\
\text { outcome against the } \\
\text { identified criteria. No } \\
\text { designer interaction }\end{array}$ & $\begin{array}{l}\text { The tool reviews the } \\
\text { design outcome and } \\
\text { modifies it without any } \\
\text { designer interaction. The } \\
\text { tool does not display } \\
\text { results to the designers }\end{array}$ & $\begin{array}{l}\text { The tool alone selects } \\
\text { the final design } \\
\text { outcome. The result is } \\
\text { presented at the } \\
\text { designer at the end of } \\
\text { the process. }\end{array}$ \\
\hline
\end{tabular}


Moreover, the taxonomy is organised according to the four GEMS functions (Srinivasan and Chakrabarti, 2010) identified in the previous section. Table 2 below presents the LOA organised as a grid with the four generic design functions (generation, evaluation, modification and selection) in a horizontal direction, for a general design outcome (Figure 2). Each cognitive function is then put in relation vertically with the five levels of automation described in Table 1.

Hence, the levels in the "generate" column refer to the creation of a design outcome, starting from a set of requirements; the levels in the "Evaluation" column, addressed the quality and importance of a design outcome; the "modify" column takes into account the activities that change a design outcome; and the levels in the "select" decide if a design outcome is acceptable or not.

\section{Examples of tools characterize in the analysis}

The following section illustrates an application of the grid to characterise the levels of automation of the tools proposed in the literature. Hence, two papers have been chosen from recent works in the domain of System Engineering and Architecture.

The logic that led to the selection of these two particular papers is based on the time frame, where only recent papers have been selected (2018-2019). In addition, the papers were chosen based on their focus in describing Designer- AI tool interaction during the design process.

Besides, the two selected papers use different AI techniques and aim to automate two different activities of the design process. In particular, the first paper, presented by Mokammel et al. (2018), seeks to automate the generation of a Requirement list. The second paper, presented in Karan and Asadi (2019), has a broader design outcome (i.e. the design of Windows in Buildings), involving several stages of the design process.

This is in order to demonstrate how the new LoA taxonomy is flexible and able to adapt to different AI tools and design outcomes, ranging from single activities to sequences of multiple activities within the design process.

However, the application of the new LoA taxonomy to the two selected paper is not exhaustive to validate the proposed taxonomy. Validation is beyond the scope of this paper, where the main objective was to generate the different levels that make up the Functions/Levels of Automation grid.

To this purpose, the first paper, presented in Mokammel et al. (2018), aims to requirement elicitation and treatment thanks to Natural Language processing and to propose a graph representation and clustering of requirements to offer representation allowing to evaluate, to select or to modify the Requirement list

As can be seen from Table 3, in general, the level of automation of the Designer-AI Tool interaction presented by the authors is low, except for the "generation" function. In fact, Level 3 is here reached [Designer (Direction) / Computer (Execution)] since the designer has to define the lists of documents to be treated in the analysis. A Level 5 [Computer Direction and Execution] would have been selected if the list of documents had been chosen by the tool itself in autonomy.

Table 3. The grid to characterize the level of design process automation for Mokammel et al. (2018)

\begin{tabular}{|c|c|c|c|c|}
\hline \multicolumn{5}{|c|}{ Design Outcome: Requirement list } \\
\hline $\begin{array}{c}\text { Level of } \\
\text { Autonomy }\end{array}$ & Generation & Evaluation & Modification & Selection \\
\cline { 2 - 5 } & & & $\mathrm{x}$ & $\mathrm{x}$ \\
\hline Level 1 & & $\mathrm{x}$ & & \\
\hline Level 2 & $\mathrm{x}$ & & & \\
\hline Level 3 & & & & \\
\hline Level 4 & & & & \\
\hline Level 5 & & & & \\
\end{tabular}

The second paper (Karan and Asadi, 2019) proposes an intelligent tool to automate the design of windows in buildings. The proposed tools aim at learning from consumer preferences on different 
design possibilities using emotional recognition. Based on these preferences, the designer has to recommend different alternatives and based on customer feedback, detail design of parameters of the window are fixed. The mathematical tool aims at maximising customer satisfaction. Indeed, it offers different visualisation of parameters combination by learning from experiences and customer satisfaction.

In this last case, as reported in Table 4, the automation is at Level 2 in the generation activity, since the designer can propose to the tool some possible designs.

Table 4. The grid to characterise the level of design process automation for Karan and Asadi (2019)

\begin{tabular}{|c|c|c|c|c|}
\hline \multirow{2}{*}{ Design Outcome: Design of Windows in Building } \\
\hline $\begin{array}{c}\text { Level of } \\
\text { Autonomy }\end{array}$ & Generation & Evaluation & Modification & Selection \\
\cline { 2 - 5 } & & & & \\
\hline Level 1 & $\mathrm{x}$ & & & \\
\hline Level 2 & & $\mathrm{x}$ & $\mathrm{x}$ & \\
\hline Level 3 & & & & $\mathrm{x}$ \\
\hline Level 4 & & & & \\
\hline Level 5 & & & & \\
\hline
\end{tabular}

In the evaluation column, feedback from customers are automatically captured, and alternatives design are proposed automatically to customers as a modification but still frame by the solution initially offer by the designer. Then the selection function is also proposed to be done in autonomy by the tool since the decision model provides an optimised design. This tool aims to support architect in routine design activities and to increase feedback from customers. The approach is to enhance the design decisions.

The two examples show how the proposed LOA can be used to analyse the Designer-AI tool interaction during the design process. The proposed taxonomy can, therefore, compare different levels of automation, using a predefined framework that can be shared by both different AI tools and for different outcomes in the design process.

It can be used by assigning an overall value to the automation level to compare different tools with different levels. Another way is to evaluate for similar design outcomes, using similar approaches, how automation is handled. In general, it is interesting to understand which are the phases of design activities that are less automated today, trying in the future to develop approaches that can in some way better facilitate the designer/tool iteration.

\section{Conclusion}

Digitalization of industry and the so-called Industry 4.0 revolution offer new opportunity to discuss design activity and supported tools. In particular, advancement in Artificial Intelligence and DataDriven Design tools are allowing to rethink the role of both Designers and the decision aid tools during the design process.

The traditional view of the designer at the centre of the design process is changing, and the tools that have been used as mere support are developing an autonomy that should be furtherly studied. In particular, what is changing is the interaction between the Designer-AI tool, and new methods for addressing the subdivision of work between the two are required.

Therefore, this paper proposes a taxonomy of LOA for the design process. The research is inspired by the research on different LOA developed in the cognitive engineering, manufacturing and robotics literature. The new taxonomy is bounded on five levels of automation, which look at different aspects of interaction and collaboration between the Designer and the AI tool during the design process. The design activities have been modelled based on the GEMS approach, which identifies four main general functions: generate, evaluate, modify and select. In order to demonstrate the application of the proposed taxonomy, two research papers have been selected from the recent literature in System 
Engineering and Architecture. The two contributions, while addressing different design outcomes and using different AI tools, verify the applicability of the new LOA.

The limitations of this paper are due to the approach not yet validated. As mentioned above, the aim of the paper was precisely to determine the basis for the definition of a taxonomy. In the future, the 5level scale will be further applied to different design outcomes, using different AI tools, and to real industrial contexts. This will validate the proposed approach.

The novelty of the proposed taxonomy is in providing a measure of automation, from different other domains to the design. Moreover, by choosing a cognitive model for the design activities, the taxonomy is closer to the way the designer behaves during the design process. This also in order to better understand how the AI tool could be better integrate and support/substitute the designer in performing his/her activities.

The taxonomy can be used in order to assess the degree of autonomy of AI tools thought for the design process. Moreover, it can also provide a way to better understand gaps of automation in different phases of the design process, so to develop more collaborative tools.

\section{References}

Billings, C.E. (1997), Aviation Automation: The Search for a Human-Centered Approach, Lawrence Erlbaum Associates, Mahwah, New Jersey, USA.

Bradshaw, J.M. et al. (2013), "The seven deadly myths of 'autonomous systems", IEEE Intelligent Systems, Vol. 28 No. 3, pp. 54-61. https://doi.org/10.1109/MIS.2013.70

Breton, R. and Bossé, É. (2003), "The cognitive costs and benefits of automation", Defence Research and Development Canadavalcartier (Quebec).

Chiantella, N. (1982), "Achieving Integrated automation through computer networks", SMA/CASA Computer Integrated Manufacturing Series, Vol. 1 No. 2, pp. 2-21.

Duncheon, C. (2002), "Product miniaturization requires automation - but with a strategy", Assembly Automation, Vol. 22 No. 1, pp. 16-20.

Endsley, M.R. and Kaber, D.B. (1999), "Level of automation effects on performance, situation awareness and workload in a dynamic control task", Ergonomics, Vol. 42 No. 3, pp. 462-492.

Finger, S. and Dixon, J.R. (1989), "A review of research in mechanical engineering design. Part I: Descriptive, prescriptive, and computer-based models of design processes", Research in engineering design, Vol. 1 No. 1, pp. 51-67.

Fitts, P.M. (1951), Human Engineering for an Effective Air-navigation and Traffic-control system, National Research Council, London.

Frohm, J. et al. (2008), "Levels of automation in manufacturing", Ergonomia-an International journal of ergonomics and human factors, Vol. 30 No. 3.

Groover, M.P. (2001), Automation, Production Systems, and Computer-integrated Manufacturing, Prentice Hall, Upper Saddle River, N.J., USA.

Inagaki, T. (2003), "Adaptive automation: Sharing and trading of control", Handbook of cognitive task design, Vol. 8, pp. 147-169.

Johnson, M. et al. (2011), "Beyond cooperative robotics: The central role of interdependence in coactive design", IEEE Intelligent Systems, Vol. 26 No 3, pp. 81-88. https://doi.org/10.1109/MIS.2011.47

Kaber, D.B. (2018), "Issues in human-automation interaction modeling: Presumptive aspects of frameworks of types and levels of automation", Journal of Cognitive Engineering and Decision Making, Vol. 12 No. 1, pp. 7-24.

Karan, E. and Asadi, S. (2019), "Intelligent designer: A computational approach to automating design of windows in buildings", Automation in Construction, Vol. 102, pp. 160-169.

Miller, C.A. and Parasuraman, R. (2007), "Designing for flexible interaction between humans and automation: Delegation interfaces for supervisory control", Human Factors, Vol. 49 No. 1, pp. 57-75. https://doi.org/ $10.1518 / 001872007779598037$

Mokammel, F. et al. (2018), "Automatic requirements extraction, analysis, and graph representation using an approach derived from computational linguistics", Systems Engineering, Vol. 21 No. 6, pp. 555-575.

Parasuraman, R., Sheridan, T.B. and Wickens, C.D. (2000), "A model for types and levels of human interaction with automation", IEEE transactions on system, man, and cybernetics - Part A: Systems and humans, Vol. 30 No. 3, pp. 286-296.

Proud, R.W., Hart, J.J. and Mrozinski, R.B. (2003), "Methods for determining the level of autonomy to design into a human spaceflight vehicle: a function specific approach", National Aeronautics and Space Administration, Houston, TX, Lyndon B Johnson Space Center. 
Ruff, H.A., Narayanan, S. and Draper, M.H. (2002), "Human interaction with levels of automation and decisionaid fidelity in the supervisory control of multiple simulated unmanned air vehicle", Presence, Vol. 11 No. 4, pp. 335-351.

Save, L., Feuerberg, B. and Avia, E. (2012), "Designing human-automation interaction: a new level of automation taxonomy”, Proc. Human Factors of Systems and Technology, 2012.

Seidel, S. et al. (2018), "Autonomous tools and design: a triple-loop approach to human-machine learning", Communications of the ACM, Vol. 62 No. 1, pp. 50-57.

Sheridan, T.B. (1980), "Computer control and human alienation", Technology Review, Vol. 83 No. 1, pp. 60-73.

Sheridan, T.B. and Verplank, W.L. (1978), "Human and computer control of undersea teleoperators", Massachusetts Inst of Tech Cambridge Man-Machine Systems Lab.

Srinivasan, V. and Chakrabarti, A. (2010), "An integrated model of designing”, Journal of Computing and Information Science in Engineering, Vol. 10 No. 3, p. 031013.

Takeda, H., Veerkamp, P. and Yoshikawa, H. (1990), "Modeling design process", AI magazine, Vol. 11 No. 4 , pp. 37-37.

Vagia, M., Transeth, A.A. and Fjerdingen, S.A. (2016), "A literature review on the levels of automation during the years. What are the different taxonomies that have been proposed?", Applied ergonomics, Vol. 53, pp. 190-202.

Williams T.J. (1999), "PERA and GERAM: Establishment of the place of the human in enterprise integration", Proceedings of IFAC Congress, Beijing, China.

Woods, D.D. (1985), "Cognitive technologies: The design of joint human-machine cognitive systems", $A I$ magazine, Vol. 6 No. 4, pp. 86-86. 